Article

\title{
On the Sustainability of Co-Authoring Behaviors in Vietnamese Social Sciences: A Preliminary Analysis of Network Data
}

\author{
Tung Manh Ho ${ }^{1,2}$ (D), Hong Kong T. Nguyen ${ }^{3}$, Thu-Trang Vuong ${ }^{2,4}$ (i) and \\ Quan-Hoang Vuong ${ }^{2,5, *}$ (iD) \\ 1 Institute of Philosophy, Vietnam Academy of Social Sciences, Hanoi 100000, Vietnam; tung.ho@wu.edu.vn \\ 2 Centre for Interdisciplinary Social Research, Western University Hanoi (ĐH Thành Tây), \\ Hanoi 100000, Vietnam; thutrang.vuong@sciencespo.fr \\ 3 Vietnam Panorama Media Monitoring, Giang Vo, Hanoi 100000, Vietnam; hongkong.tnguyen@gmail.com \\ 4 Sciences Po Paris, Campus de Dijon, 21000 Dijon, France \\ 5 Université Libre de Bruxelles, Centre Emile Bernheim, 1050 Brussels, Belgium \\ * Correspondence: hoang.vuong@wu.edu.vn or qvuong@ulb.ac.be
}

Received: 18 October 2017; Accepted: 18 November 2017; Published: 20 November 2017

\begin{abstract}
The topic of sustainability has mostly been tied to economic development and environmental protection, yet not much attention has been paid to the need for high problem-solving capacity as this underlines both issues. One of the most straightforward ways to improve problem-solving capacity is to nurture 'productive and enduring', i.e., sustainable, scientific communities. The study examines the co-authoring behaviors of 412 Vietnamese social scientists over the 2008-2017 period via social network analysis to determine if these researchers have formed sustainable scientific communities, using Scopus data. The dataset provides an insightful look into the predominant form of collaboration, i.e., co-authorship, within the Vietnamese social science research communities. Through basic network metrics such as density and clustering coefficient, the study hypothesizes that the socially sustainable research communities are those with low clustering and high density. As any scholar's position in a network can be specified by three quantities: the number of publications, connections, and years in research, the distance metrics from the most productive to the rest are computed and compared. The study hypothesizes that if the distance is too large; it reflects the socially unsustainable situation in the network. The results indicate that certain level of social unsustainability exists in social sciences groups in Vietnam. Though the results are only indicative, it has opened up a fertile space for future inquiry into this matter.
\end{abstract}

Keywords: publishing behavior; co-authoring behavior; sustainable scientific communities; social sustainability distance; social network analysis; Vietnam

\section{Introduction}

In April 2017, the Vietnamese Ministry of Education and Training (MOET) issued a new regulation requiring all doctoral students to have papers published in Scopus and Web of Science-Indexed journals, and Ph.D. supervisors to have at least one international publication [1]. This is in line with a Ministry of Science and Technology policy, effective from 2008, to prioritize funding for strong research groups [2,3]. At the same time, the public has been intensely interested in the debate on the proposal to reform the standard of the highest academic titles in Vietnam: Professor and Associate Professor. In the debate, the central issue is about the role of international publications in judging whether a Vietnamese academic is worthy of these honorary titles [4,5]. Several popular stories in the Vietnamese press have exposed the absence of Vietnamese universities in Asia's top 300 and the low quantity of international 
publications by Vietnamese researchers and research institutions, especially in social sciences and humanities [6,7]. For example, many have questioned the Vietnam Academy of Social Sciences (VASS), which is touted as one of the top governmental research institutions, for spending more than USD 90 million in five years until 2016, only to publish 22 Web-of-Science-indexed papers in total [8,9]. In this context, many experts agreed that change is necessary to create more internationally integrated, productive and sustainable research communities in Vietnam [10]. The end goal is clear, yet, how to embark is uncertain for both the public and policy-makers.

An important reason for such uncertainty is the lack of actionable hard data and insights on the international publication of Vietnamese researchers in social sciences and humanities. One study shows that in South East Asia, the total research output in Vietnam is relatively low, with the rate only equivalent to $13 \%$ of Singapore and $29 \%$ of Thailand in the period of 1991-2010 [11,12]. It is notable that the share of international co-authorship takes up $77 \%$ of the total publications $[13,14]$ and most of the leading authors are not from Vietnam [13]. Regarding social sciences and humanities in Vietnam, a new study shows that the number of publication is strongly correlated with leading authors aged between 40 and 50, but is not correlated with their gender [15]. Regarding collaboration trends in Vietnamese social sciences, it is shown that the number of Vietnamese leaders in research groups is still very small and about $75 \%$ of the Vietnamese authors never attempted publishing solo [16]. Another study on co-authorship network among Vietnamese social scientists demonstrates how sparse the connections among these researchers are, though these connections depend heavily on a group of intellectual elites, who consist of well-connected, productive and socially important individuals [17]. The prevalence of international co-authorship and the scattered co-authorship connections among Vietnamese social scientists provide an interesting contrast. As pointed out by Vuong and Napier [18,19], Vuong [20], in a Confucian society such as Vietnam, criticisms of an innovative idea could be seen as a personal distrust in the person who proposes it. It could be the case that collaboration among Vietnamese scientists, who supposedly operate in the frontier of innovation and creativity, might suffer as a result of this cultural burden. In many ways, this background suggests a level of unsustainability in the collaboration among Vietnamese social scientists. Thus, for Vietnamese public and policy-makers to improve the weak research capacity in social sciences, it is vital to understand whether the existing social scientific communities are socially sustainable, and to find a means to identify the sustainable research groups. By collecting and analyzing data using network statistical analysis on co-authorship networks among Vietnamese social scientists who have successfully published in the Scopus-indexed journals, this study seeks quantifiable criteria that help identify sustainable scientific communities in Vietnam.

By understanding these research networks, this will hopefully provide a basis for better science funding, and thereby, improve the capacity for problem-solving in Vietnam.

\section{Literature Review}

The literature review will firstly provide a sufficient context for grasping the concept of "sustainability" by clarifying its definition and approaches. The purpose is to make clear how sustainable scientific communities are connected to sustainability as a whole.

\subsection{What Does Sustainability Mean?}

Sustainability and sustainable development are two very popular, yet vague, concepts that have come about in recent decades. Indeed, for many, they are comparable to the term democracy, for its ambiguity and desirability [21]. The definition first offered in the Brundtland Report (Our Common Future) on sustainable development as the kind which "meets the needs of current generations without compromising the ability of future generation to meet their own needs," has received much criticism for its vague nature [22-26]. However, there are also arguments supporting a certain level of ambiguity since it opens up a possibility for flexible negotiations [23] and helps avoid unhelpful ideological battles related to these concepts [27]. 
What many definitions have in common is the growing awareness of the interconnectedness between human society and nature: human well-being depends on a clean, hospitable natural environment. In 1992, about 1,700 scientists from the Union of Concerned Scientists (UCS), including 102 Nobel Laureates, joined hands to call for a fundamental change by detailing that our current practices, if left alone, could inflict great harm to the environment and human civilizations [28]. Along with this line of reasoning, there have been several alarming discussions on the untenable relationship between human population growth and resources management, which could lead to the eventual collapse of human civilization [29-33].

Another dimension of sustainability is the case against severe economic inequality, which is referred to in the Brundtland Report [22] and Holden et al. [24] as promoting intra-generational equity. Though sustainability is a relatively new concept, past thinkers such as Karl Marx have long considered it a threat toward a stable and thriving society [34]. This debate has recently been revived by renowned economists such as Stiglitz and Piketty [35,36] and scholars across a range of disciplines [33,37,38]. With rapid progress in technology, how to manage technological risks has been added as a new dimension to the problem of how to sustain human society long into the future [39-42].

Indeed, however vague sustainability appears to be, it remains a useful concept in capturing a wide range of problems which are fundamental to the long-term development of human society. Next, the existing approaches to solve these sustainability problems will be reviewed.

\subsection{Different Approaches in Solving Sustainability Problems}

This paper groups the approaches to solving sustainability problems into three broad categories: (i) institutional level, (ii) individual level, and (iii) technological fix. While there is considerable overlap among these categories, this classification offers a useful way to understand the landscape of approaches toward the sustainability problem.

First, for the institutional level, the main focus is on changing conceptual frameworks, policies, and behaviors of institutions to be more effective in striking a balance between securing long-term human survivals and satisfying the current needs of human society. Elkington suggested the Triple Bottom Line model for businesses to assess and direct their sustainable practices, in which profit as a conventional bottom line is added together with the planet and the well-being of people [43]. Some argue that it is possible to think of sustainability as an all-encompassing concept for both socio-economic and environmental dimensions by simply adding an Ecological Footprint [24]. Other suggestions include Max Tegmark's argument for a switch in an institutional level from the learning-from-past-mistakes framework to a more proactive "security engineering" approach [44], namely, the case made by Bettencourt and West [45] for adopting a new quantitative understanding of urban living in policy-making in order to arrive at "a sustainable, creative, prosperous, urbanized world expressing the best of human spirit".

Second, on the individual level, the focus lies in changing the behaviors and lifestyles of each individual so as to increase global sustainability. For example, the green living movement calls for each individual to be more aware of his or her relationship with the environment and thus adopt a more environmentally friendly lifestyle: using public transport rather than driving, classifying household trashes, boycotting eco-unfriendly products, curbing excessive consumptions, etc. However, studies show that such policies only succeed in a limited way [46] for there seems to be no direct way to encourage people to adopt a more eco-friendly lifestyle [47-50]. In addition, research has shown when it comes to sustainable choices and behaviors; human psychology seems to be naturally prone to many mental barriers in adopting a more sustainable lifestyle: limited awareness, abstractness, sunk costs fallacy, experts' suspicion and fear of change, amongst others [51-56].

Finally, technological fix, which is centered on scientific discovery and technological innovation, is a relatively less discussed approach. Deutsch in 2011 discussed the concept of sustainability in the context of how to maintain an open-ended quest for knowledge creation. In this view, there is no way to foresee how new problems could arise from new scientific ideas and solutions to existing problems. 
Thus, the only sustainable way to organize a society is to nurture rapid progress in science and technology; in this process, a vibrant, creative and productive community of scientists is necessary [57]. Geoffrey West arrived at the same conclusion from a different line of reasoning: by applying network theory to mathematically study growth in biological systems, and human systems such as corporations and cities. He found that it is possible to have an open-ended growth for social systems such as cities under one condition: continuous innovation [58,59]. West called for a grand unified theory of sustainability-a science that is quantitative and predictive-as he saw the same universal law of scaling can be applied to both the natural and human worlds [60].

\subsection{Social Sustainability, Scientific Communities and Social Network Analysis}

As can be seen from the previous section, whether one chooses to address the problem in a personal or institutional level or by finding a technological fix, the role of creative problem solving and innovation is central to creating a more sustainable future. Hence, it is important to ask how communities of scientists operate and how to identify sustainable communities-the enduring and productive ones. As communities are essentially networks, in this investigation, social sustainability and social network analysis can be fruitful concepts to explore.

Researchers have used the concept of social sustainability to investigate a wide range of subjects: sharing economy, supply chain, construction projects, community resilience, etc. [61-65]. However, similar to sustainability and sustainable development, social sustainability suffers from the problem of ambiguity and context-dependence, it is almost chaotic to survey the literature review related to this issue $[66,67]$. There have been many attempts to develop measures and indicators for social sustainability; however, just like the concept, the measures cover a broad range of aspects [68]. As Turcu pointed out, the indicators are manifestations of the underlying local perspectives regarding sustainability [69]. On the one hand, this situation implies that the problem of ambiguity is not going away anytime soon, on the other hand, it also means there is enough space and flexibility in this line of research to apply the concept in the most constructive way.

Meanwhile, social network analysis, as a technique, has been employed widely to study the structures of scientific collaboration and dynamics. Newman showed scientific collaboration networks seem to have the 'small world' properties when he applied this technique to the data of biomedical research, physics, and computer science [70]. By studying citation networks, a study was able to uncover the landscape of sustainability science: there are 15 main research clusters such as rural sociology, tourism, forestry, ecological economics, urban planning, wildlife, etc. [71]. Similarly, Moody (2004) revealed that in sociology, researchers who do quantitative work tended to work with non-quantitative counterparts by studying 30 years' worth of data of sociology collaboration networks [72]. Application of social network analysis is also useful in predicting scientific performance. For example, a group of Taiwanese researchers found that position in a co-authorship networks can help predict citations of publications [73]. In China, a research team also found the same pattern when examining co-authorship network effects toward citation counts using library and information science data [74].

Indeed, there have been many attempts to utilize social sustainability and network analysis together. A study analyzed networks data and data on perceptions revealed that collaboration networks and sustainability perceptions are important in evaluating the implementation of climate change adaptation [75]. Another study applied network analysis in studying the interests of multiple stakeholders in construction projects in Saudi Arabia and concluded that as the needs of diverse stakeholders were satisfied, the situation of social sustainability improved for the construction projects [63]. However, there is no attempt yet at utilizing the two concepts in the context of scientific communities. Thus, this paper will explicate how useful the technique of network analysis is in providing a quantitative understanding of social sustainability within the social science communities in Vietnam. 
Standard network measures, such as clustering coefficient (transitivity), have been shown to have straightforward mathematical relation to the spread of information in a network-the higher the cluster, the slower information spread [76]. And in sustainable scientific communities, one can reason that information, e.g., data, knowledge, expertise, and experiences, should be communicated efficiently. Thus, the clustering coefficient would offer an indirect way of assessing the status of social sustainability of research communities. Moreover, in a co-authorship network, a scholar's position can be defined by three types of quantity: the number of publications, connections, and years of research. As a result, it is possible to calculate the distance from the most productive member of a network to any other members of the network. This distance, referred to as "social sustainability distance" (SSD), might be meaningful in investigating the social sustainability of the scientific network in question.

By collecting attribute data and relational data about 412 Vietnamese social scientists between 2008 and 2017, then constructing a co-authorship network of these scholars, this paper will attempt to answer two research questions:

RQ1: Through clustering coefficient and density, what can be stated on the status of social sustainability in Vietnamese social scientists' communities?

RQ2: What does the $S S D$ tell us about the social sustainability of Vietnamese social scientists' communities?

\section{Materials and Methods}

\subsection{Conceptualization of Research Questions}

The concept of sustainability in research networks has never been explored; therefore, it is important to clearly define what is meant by saying that a research network is sustainable. Normatively speaking, a sustainable research network should: (i) be efficient in transferring scientific knowledge and expertise, (ii) remain well-connected even if a few members of the network are removed, (iii) be comprised of productive members, and (iv) that these members should collaborate with each other many times over a long period of time. In other words, a socially sustainable research network should be one that is productive and enduring. Though it can be relatively intuitive and straight-forward to comprehend what would make a research network sustainable, it is hard to quantify the criteria. Here, the technique of social network analysis offers a novel way to solve this problem. Before getting to the criteria expressed in social network analysis language, it is useful to understand the basic terminologies of the technique.

A social network is defined as a collection of individuals, each of whom is related to others by one or more different kinds of relations such as friendship, kinship or co-authorship [77]. And network analysis is an emerging field, based on the application of various mathematical tools and methods on the problems related to the network. A graph or a network $G=(V, E)$ is a mathematical structure consisting of a set $V$ of vertices (or nodes) and a set $E$ of edges (or links); elements of $E$ are links between a pair of distinct vertices belongs set $V$. In this study, a vertex represents a Vietnamese social scientist. An edge represents a co-authorship connection between two distinct Vietnamese social scientists. The number of edges incident upon a vertex is called a vertex degree. The degree is an important concept in this study because it is used in a measure that helps identify sustainable research networks.

In this paper, we will use the words node, vertex, Vietnamese social scientist, researcher, scholar, and scientist interchangeably. Similarly, edges, links, and connections are also equivalent in meaning. The words such as network, graph, research network, and co-authorship network are also interchangeable. To see how these seemingly irrelevant concepts can be useful in identifying sustainable research networks, let us consider the way that network analysis enables us to quantify the different aspects of a sustainable network.

First, to get a sense of how efficient information in a network is communicated, one can study how many connections there are in a network. This can be measured by the concept of density, the number of realized connections divided by the number of potential connections. One can assume that the 
higher the density, the more information can flow in a network. However, the measure of density might not reflect the full picture because the higher the number of members of a network, the more potential connections, and thus, the density can decrease as a result. Hence, it is important to view a network from another angle.

Another angle to get a sense of how efficiently information can be spread in a network is the clustering coefficient, namely, the likelihood that a connected triple will close to form a triangle. In network statistical analysis literature, it is well-known that the higher the clustering coefficient, the less efficiently information will spread in the networks [76]. Thus, in the context of studying the sustainability of a research network, one can assume if a network has a low clustering coefficient, it is likely that information will be better communicated in this network.

Through density and clustering coefficient, one can catch a glimpse into how effective scientific knowledge can spread in a network. However, ultimately, one must understand the end result of this process of knowledge dissemination, which is the gap between the most productive researcher or the most connected and others in the network. In a sustainable network, this gap should not be too big. To measure this gap, we have developed a measurement for the distance between the most productive member of a research network and the rest of the network.

One can reason that the numbers of connections in a co-authorship network and the number of research years would have an effect on the productivity of a researcher. For example, the longer a person has been doing research, the more likely he or she can increase his or her productivity; or the more people a researcher co-authors with, the more likely he or she gains access to more ideas and knowledge, which can potentially result in a gain in productivity. It can be seen that three quantities: number of publications, number of co-authorship links, and research years would constitute a vector that specifies any social scientist in a research network. Hence, one can compute the Euclidean distance from the vector that identifies the most productive scholar to other vectors that pick out any other nodes in a network. Whether this distance is large or small would be a telling sign if a research network is sustainable or not.

We believe that these network metrics together will provide a quantitative method to identify sustainable research networks, as shown in Figure 1.

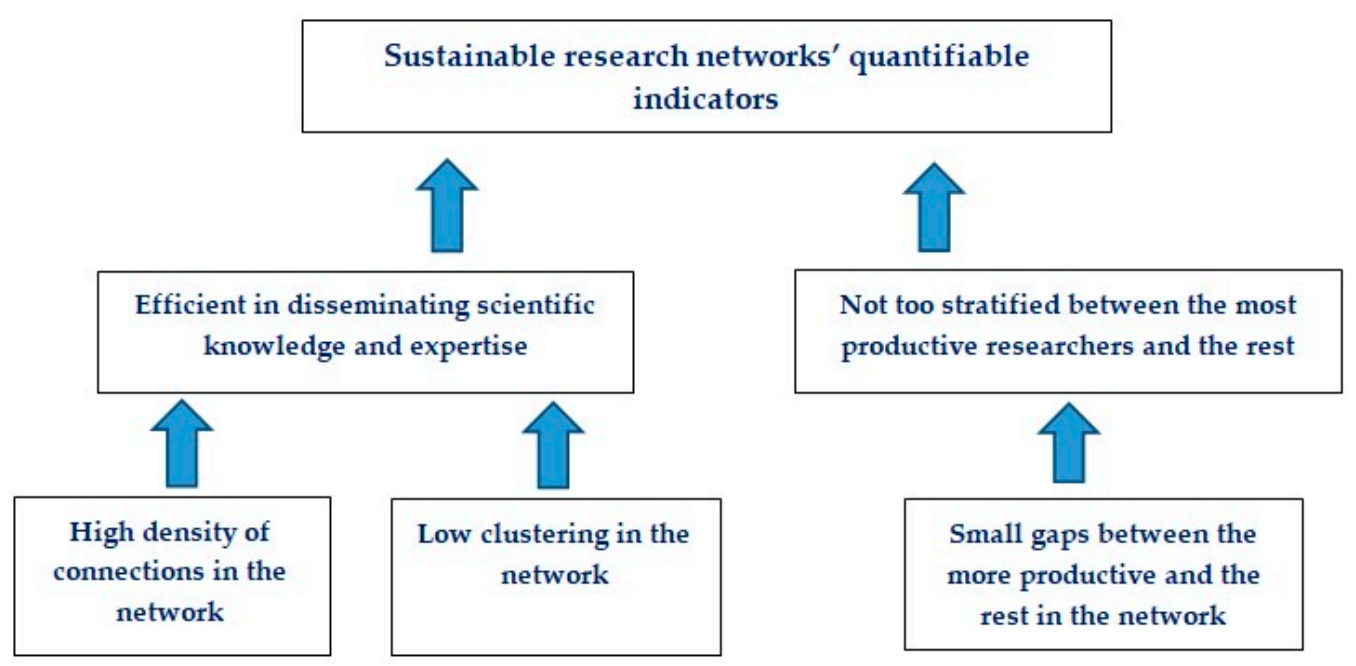

Figure 1. Conceptualization of the approach to possible sustainable indicators.

\subsection{Materials: Attribute Data and Relational Data}

The data for this study was derived from a dataset on the productivity of Vietnamese scientists in the field of social sciences and humanities collected by Vuong and Associates. The investigation, which took place within five months from February to July 2017, was conducted under the license V\&A/03/2017, issued on 15 March 2017. 


\subsubsection{Attribute data}

We set out to collect the data on Vietnamese researchers working in social sciences and humanities who have published in Scopus-indexed journals. There are three reasons we chose Scopus. Firstly, the Vietnamese government has used Scopus-indexing as a criterion for science funding since 2008 [78]. Second, substantial parts of Scopus data are free and transparent; one can access Google Scholars to look up the publications and use open data sources such as Scimagojr and Scopus to check the journals. And finally, Scopus indexed nearly 22,600 active titles, almost twice the number of its counterpart, Web of Science $[79,80]$.

Next, the criteria of for a researcher to be considered a legitimate subject for data collection were determined. The criteria are:

a. A researcher must be a Vietnamese national

b. He or she satisfies either or both of these two conditions:

- Have been affiliated with a Vietnamese institution;

- Have published at least one paper on a social scientific issue related to Vietnam.

Being clear on the criteria, we then set out to collect attribute information of the researchers that satisfy the requirements. The result of the data collection process is a complete dataset of 412 scholars' details, consisting of: (i) age, sex, region; (ii) affiliations; (iii) fields of study; (iv) the number of publications in Scopus, (v) the number of research years since the Master graduation; (vi) the number of researchers they collaborated with; (vii) whether or not they have the title of "Professor/Assoc. Professor". To make sure the data is reliable, the research team collected data from various sources such as personal and institutional websites of scholars, journals' websites, Google scholars, and Scopus database. Then by comparing information in these online sources (Google scholar versus Scopus, personal sites versus organizational websites, etc.), we were able to eliminate potential errors. For instance, different versions of a Vietnamese name can result in two IDs for one person, or a person has Vietnamese name but is not a Vietnamese national. In the end, the clean set of data constitutes the "Nodes list" ("20170725_net412_ NODES.csv"), which contains the attribute information of each author.

\subsubsection{Relational Data}

From the data available after making the Nodes list, an "Edges list", ("20170729_net412_LINKS.csv") which contains relational data, is constructed. When two researchers co-author a paper, they are considered to have a co-authorship link. Every time the same two authors appear together in a paper, it is counted toward the "weight" of the link. Figure 2 shows an example of how the edges list is derived from the original data. As an example, in the first row of the table on the left side, a published paper being co-authored by scientists ID s004, s076 and s079 is registered. Then, on the right side, the co-authorship links among these three scholars are documented; and the weight is the count of how many times each pair co-authors. The data was then processed and analyzed using statistical software R (v3.3.1). 


\begin{tabular}{|l|c|c|c|}
\hline \multicolumn{1}{|c|}{ Title } & year & Journal & ID \\
\hline $\begin{array}{l}\text { Does Economic Inequality Affect the Quality } \\
\text { of Life of Older People in Rural Vietnam? }\end{array}$ & 2017 & $\begin{array}{c}\text { Journal of } \\
\text { Happiness } \\
\text { Studies }\end{array}$ & s076;5004; s079 \\
\hline $\begin{array}{l}\text { The Effect of Having Children on Women's } \\
\text { Marital Status: Evidence From Vietnam }\end{array}$ & 2017 & $\begin{array}{c}\text { Journal of } \\
\text { Development } \\
\text { Studies }\end{array}$ & s004; s046 \\
\hline $\begin{array}{l}\text { Does firm privatisation benefit local } \\
\text { households? The case of Vietnam }\end{array}$ & 2015 & $\begin{array}{c}\text { Post-Communist } \\
\text { Economies }\end{array}$ & s005; s004; s079; 5080 \\
\hline $\begin{array}{l}\text { Firm agglomeration and local poverty } \\
\text { reduction: evidence from an economy in } \\
\text { transition }\end{array}$ & 2016 & $\begin{array}{c}\text { Asian-Pacific } \\
\text { Economic } \\
\text { Literature }\end{array}$ & s005; s004; s076 \\
\hline
\end{tabular}

(a)

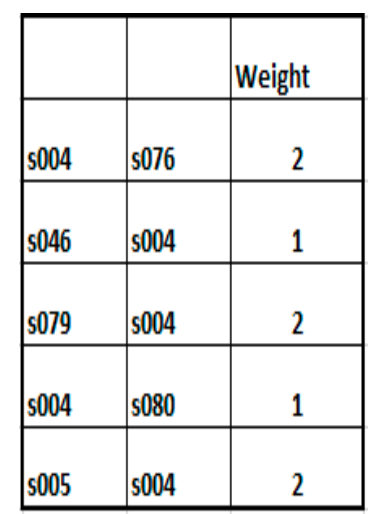

(b)

Figure 2. An example of the process of deriving relational data from the original dataset. (a) The table shows an example of recording article titles and their relevant properties. (b) The table describes how relational data is created from table (a) (Adapted from [17]).

The data for Net1 to Net20 were manually extracted from the full dataset. Nodes lists and edges list for these 20 networks were built by picking relevant edges and nodes from the original lists; all of which are available in the folder 20 Networks' Data.

\subsection{Method of Analysis}

There are several reasons why we chose the method of statistical analysis of social network data for this study. First, the four features of social network analysis as put forth by Linton Freeman, namely a "structural intuition, systematic relational data, graphic images and mathematical or computational models", are all suitable for the purpose of this study [81]. Second, we are naturally inclined to wonder what kind of interactions occurs among Vietnamese social scientists given the pervasiveness of co-authorship [16]. This leads us to expect that social network analysis would be a match with our interest to achieve a holistic and quantitative view of the characteristics of the co-authoring behavior of Vietnamese social scientists: how densely co-authoring connections occur, how clustering would affect the productivity of a co-authoring network, how socially sustainable it is. Another important aspect is the possibility of visualization of research networks. With the support of statistical software, graphic representations of research networks could be created; hence, not only we could learn from all the rigorous numerical analysis, but we could also achieve a more intuitive understanding of the interactions among actors in a co-authoring network. It is indeed not difficult to see the advantages that the method offers, given our research questions.

As this study is strictly limited to the co-authoring behavior of Vietnamese scholars only, besides the advantages, there are a few caveats regarding the scope of analysis. First, it is likely that some features of research networks could be lost when the co-authorship connections with foreign scholars are not taken into account. To illustrate, a foreign researcher might co-author with a few Vietnamese scholars, but these Vietnamese might not publish together. This will result in some number of missing links. The aggregate effects of this phenomenon can make the network appear sparser and less clustering than in reality. Second, the history of network analysis began with problems in fields such as mathematics, chemistry, electrical circuits, operational research, and computer science before they are applied to study the network of people [82]; consequently, the technique is not fully developed and matured. It is wise to keep in mind that there might well be inherent shortcomings to the explanatory power of the technique. However, considering both pros and cons, we believe social network analysis' advantages out-weigh its limitations, in conjunction with other types of techniques, such as those provided in $[83,84]$. 
Next, we will turn to the formulas for calculating the network metrics that would help us to decipher the overall characteristics of co-authoring behavior among Vietnamese social scientists.

\subsubsection{Standard Network Measures}

The formula to compute density of a network is:

$$
\text { density }=2 l /[n(n-1)]
$$

where $l$ is the number of edges/links exists in a network, and $n$ the number of nodes in the network. The formula to compute clustering coefficient is:

$$
c l_{\mathrm{T}}(G)=3 \tau \Delta(G) / \tau_{3}(G)
$$

in which $\tau \Delta(G)$ is the number of triangles in the network $G$; and $\tau_{3}(G)$ the number of connected triples, the subgraphs consist of three vertices connected by two edges. As shown in the literature review and the conceptualization of the research question, low clustering coefficient would suggest knowledge in a research network is disseminated well.

\subsubsection{A Proposed Measure of Social Sustainability Distance}

As mentioned above, in a sustainable research network, the gap between the most productive researchers and the less productive ones should not be too big. We noticed that a researcher can be specified using three quantities: number of publications, number of connections in a network, and number of years in research, as provided by Equations (1) and (2). Thus, to quantify the gap, we propose a formula to compute the Euclidean distance from a three-dimensional vector that specifies the most productive scholar to other vectors that pick out any other nodes in a network:

$$
S S D=\sqrt{\left(x_{\max }-x_{0}\right)^{2}+\left(y_{\max }-y_{0}\right)^{2}+\left(z_{\max }-z_{0}\right)^{2}} .
$$

In Equation (3), $\left(x_{\max }, y_{\max }, z_{\max }\right)$ is a vector represent three attributes of the most productive member in a network: $x_{\max }$ stands for the total number of publications, $y_{\max }$ stands for the total number of co-authorship connections that researcher possesses, $z_{\max }$ stands for his or her research years. $\left(x_{0}, y_{0}, z_{0}\right)$ is a vector representing the same three values: publications, connections, and research years that define any author in a research network.

In this study, for each co-authorship network, we compute the distance in five scenarios:

1. most productive researcher to the vector consists of the mean value of all three quantities;

2. most productive researcher to the researcher who has the median value of the network in terms of publications;

3. most productive researcher to the researcher who is in the min value in terms of publications;

4. most productive researcher the researcher who has the second highest number of publications;

5. most productive researcher to the mean value of the low productivity group, those with equal or fewer than three publications.

It is hoped that by calculating the SSD as a characteristic of a co-authorship network, then comparing this characteristic among different networks, interesting patterns regarding the social sustainability of research networks will emerge.

\section{Results}

\subsection{Standard Network Metrics and Visualization}

First, it would be useful to visualize the co-authorship connections that exist among all 412 Vietnamese social scientists in our sample. All 412 nodes and their edges are plotted on a graph 
(called Net412) using "iGraph" package in R (v3.1.1), as shown in Figure 3. As node size represents the total articles a researcher has published, interesting patterns emerge. In most of the sub-networks or research communities, the most productive researchers seem to always be central to many different connections. Lying in the top corner of the circle in both figures are 125 researchers who either work alone or work with foreigners. The middle of the circle is occupied by small groups of researchers: size $2-9$, which takes up about $40 \%$ of the total population. In the lower corner, there reside the large groups, comprising at least 10 members per group. These groups account for about $30 \%$ of the population.

Having glimpsed the structure of the network of 412 Vietnamese social scientists, one can then examine the question of social sustainability in more detail by looking at the properties of each scholarly community. Next, 20 communities with at least 5 members each are manually extracted from the total dataset (the data files for these communities can be found in the folder " 20 Networks' Data" and "R-commands and figures for all nets"). Each of these subgroups is considered a network in and of itself. In Table 1, the standard network metrics of these networks are summarized.

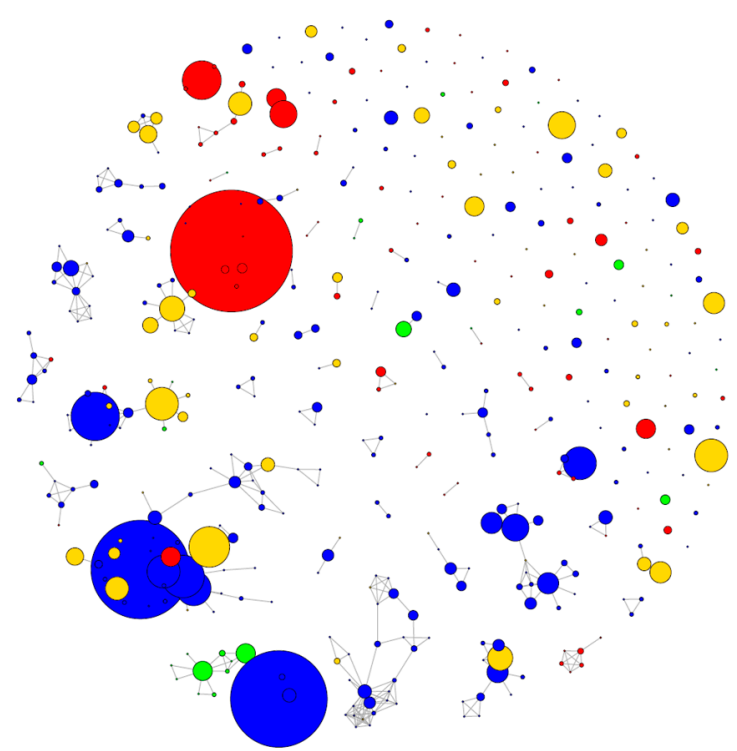

(a)

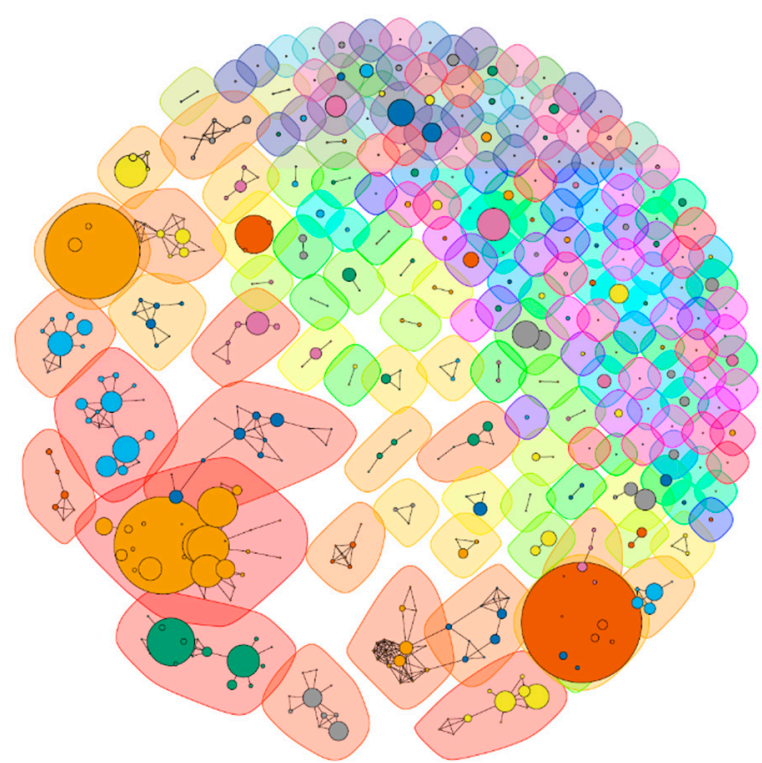

(b)

Figure 3. Net412-a visualization of all 412 Vietnamese social scientists in two modes: (a) Node colors based on regions, in which blue is for north, red is for south, green is for center, gold is for overseas; (b) Node colors automatically generated by community detection algorithm, which yields 181 communities. There are 125 communities of only one member, the remaining is communities with more than two members. (No. nodes $=412$; No. links $=401$; Density $=0.0047$; Clustering Coefficient = 0.59; Mean degree = 1.95; Mean publications = 3.56; Median publications = 2). 
Table 1. A total of 20 (sub)networks of Vietnamese social scientists and their network metrics.

\begin{tabular}{|c|c|c|c|c|c|c|c|}
\hline Network & Density & Clustering Coefficient & Mean Degree & Mean Publication & Median Publication & No. Nodes & No. Links \\
\hline Net1 & 0.29 & 0.51 & 2.91 & 3.91 & 2 & 11 & 18 \\
\hline Net2 & 0.31 & 0.44 & 2.80 & 3.90 & 1 & 10 & 14 \\
\hline Net3 & 0.33 & 0.00 & 2.00 & 4.86 & 2 & 7 & 7 \\
\hline Net5 & 0.70 & 0.80 & 2.80 & 4.80 & 6 & 5 & 7 \\
\hline Net6 & 0.36 & 0.71 & 6.53 & 2.00 & 1 & 19 & 62 \\
\hline Net7 & 0.33 & 0.67 & 3.23 & 2.64 & 1 & 11 & 18 \\
\hline Net8 & 0.11 & 0.30 & 2.97 & 7.10 & 2 & 29 & 43 \\
\hline Net11 & 0.53 & 0.75 & 2.67 & 2.33 & 2.5 & 6 & 8 \\
\hline Net12 & 0.24 & 0.52 & 3.33 & 4.60 & 3 & 15 & 25 \\
\hline Net13 & 0.73 & 0.88 & 3.67 & 1.67 & 1.5 & 6 & 11 \\
\hline Net14 & 0.43 & 0.57 & 2.57 & 2.14 & 2 & 7 & 9 \\
\hline Net15 & 0.60 & 0.60 & 2.40 & 15.00 & 4 & 5 & 6 \\
\hline Net16 & 0.33 & 0.38 & 2.67 & 3.78 & 2 & 9 & 12 \\
\hline
\end{tabular}

In Table 1, each network of Vietnamese social scientists is represented by a series of different numbers. To aid our understanding, four most noticeable communities are chosen and plotted in the next two figures: one with highest number of nodes and one with highest number of links in Figure 4; one with highest number of mean publications and one with lowest number of global clustering coefficient in Figure 5 (The R commands for Figures 4 and 5 and the figures for all the nets that do not appear in the final paper can be seen in Dataset 6, 7 and 9). In Figures 4 and 5, node size represents the number of publications; color is based on gender, blue for female and red for females; edges are links connect the nodes.

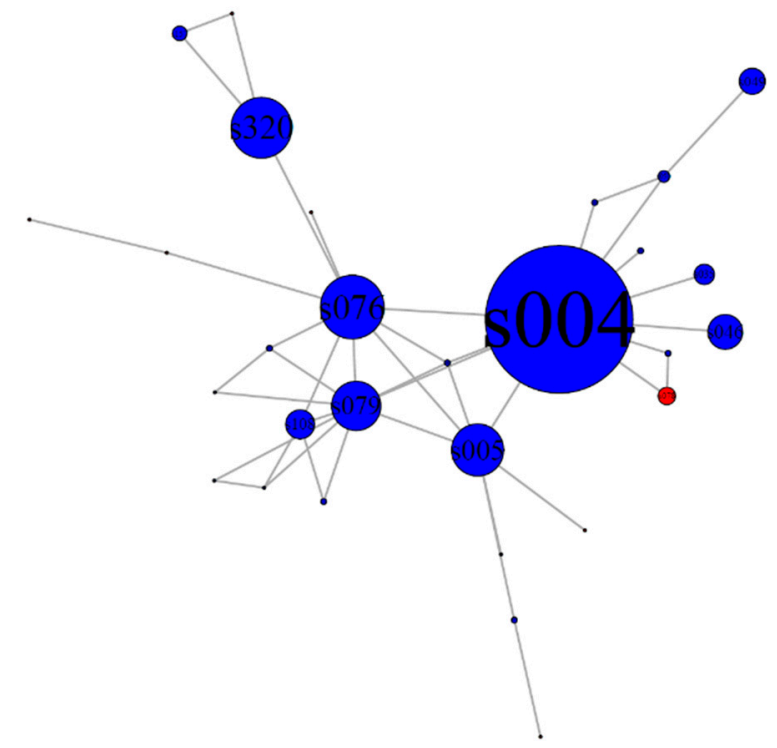

(a) Net8 is a community with the most researchers.

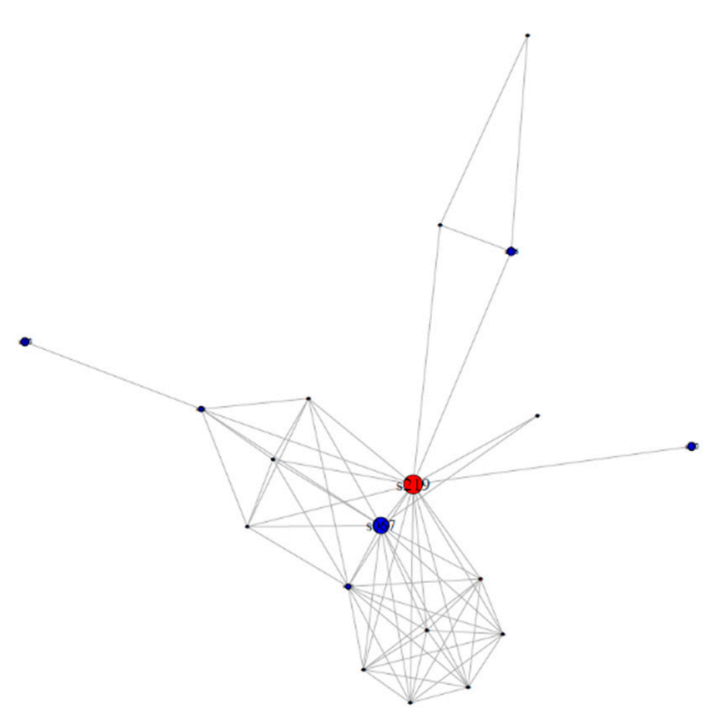

(b) Net6 is a community with the most links.

Figure 4. Two research communities among 412 Vietnamese social scientists standing out for the highest number of members and links (a) Net8: Nodes $=29$; Links $=43$; Density $=0.11$; Clustering $=0.33$; Mean degree = 2.97; Mean publication = 7.1; Median publication =2; $(\mathbf{b})$ Net6: Nodes = 19; Links = 62; Density $=0.36$; Clustering $=0.71$; Mean degree $=6.53$; Mean publications $=2 ;$ Median publication $=1$ [Adapted from 17].

In Figure 4, Net8 and Net20 are compared, as they are quite comparable in terms of nodes and links. In terms of clustering and density of connection, Net6 is higher than Net8 in both aspects; 
0.36 vs. 0.11 in density, 0.71 vs. 0.33 in clustering coefficient. One can recognize the contrast between the size of the nodes of Net8 (which has the most nodes) compared with Net6 (which has the most links). Net8 has more productive researchers in it; the fact is, Net8 has 29 members but the mean number of publication is 7.1, while Net6 has 19 members, but the mean of publication is 2, which is equivalent to one-third of the former.

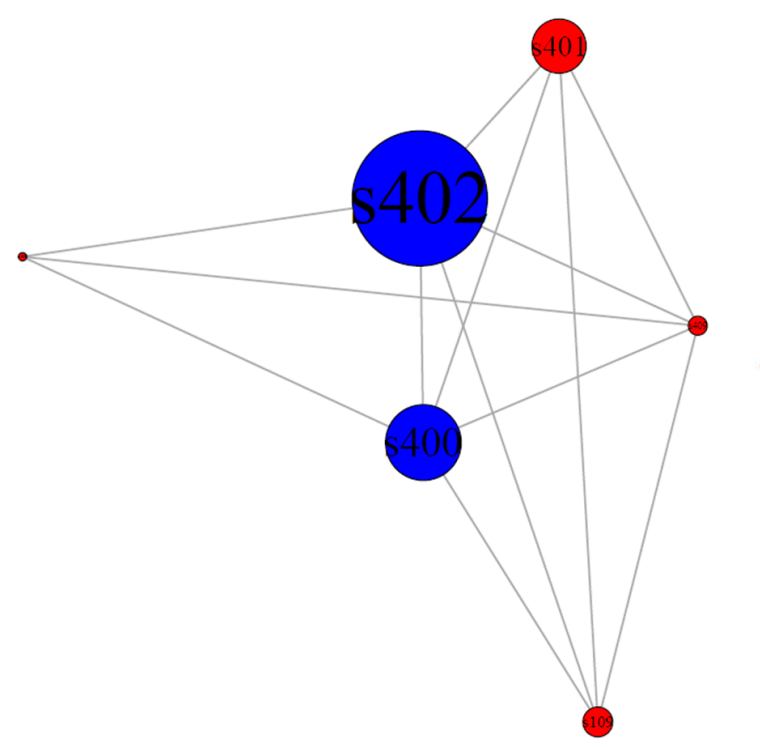

(a) Net20 is a community with the highest density of connection.

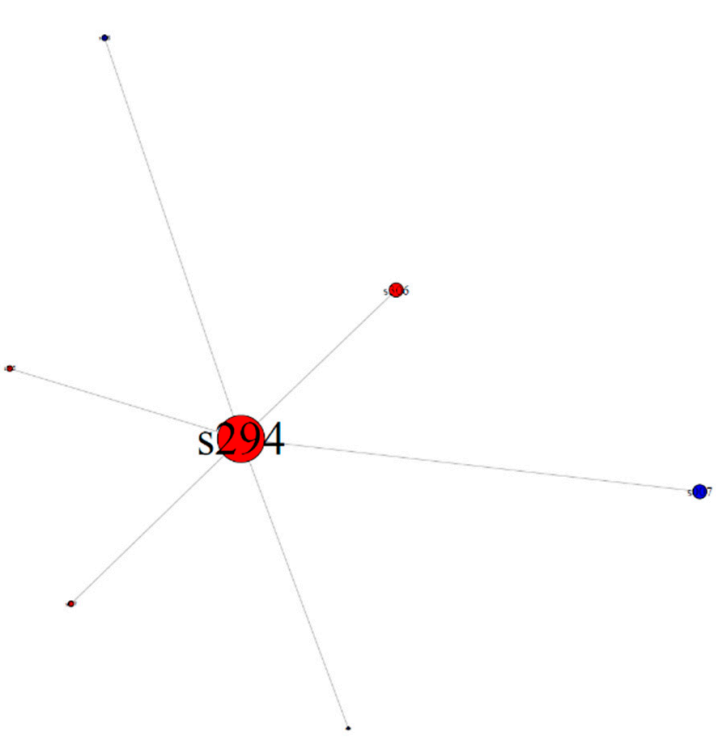

(b) Net3 is a community with no clustering coefficient.

Figure 5. Two research communities among 412 Vietnamese social scientists standing out for the highest density of connections. (a) Net20: Nodes =6; Links = 13; Density = 0.87; Clustering = 0.87; Mean degree $=4.33$; Mean publication $=19.83 ;$ Median publication $=15.5 ;(\mathbf{b})$ Net3: Nodes =6; Links = 7; Density $=0.33$; Clustering $=0$; Mean degree $=2$; Mean publication $=4.86$; Median publication $=2$.

In Figure 5, Net20 and Net3 are compared as they are also comparable in terms of nodes and links. The most visible pattern is the contrast in clustering. The clustering coefficient of Net20 is 0.87 , while the number of Net 3 is zero. Net 20 consists of more productive members, and everyone collaborates with each other. Net3 is centered around the most productive member of the group. In terms of the mean of publication, Net20 is about five times as much as that of Net3, 19.83 vs. 4.86.

Although there is no clear pattern in the data, our assumption is in a sustainable research community, information (knowledge, expertise, and experience) should be communicated efficiently; and for that to happen, the working hypothesis is the community should be low in clustering coefficient and high in density, in network metrics. That means, if we plotted a graph, in which the vertical axis is clustering coefficient, horizontal axis is density and each network is represented by a circle whose size is determined by its mean number of publications, we would be able to identify the bigger circle on the lower right quadrant of the chart to be our candidates for sustainable research networks. In Figure 6, density, clustering coefficient and the mean number of publications are plotted to investigate the hypothesis. 


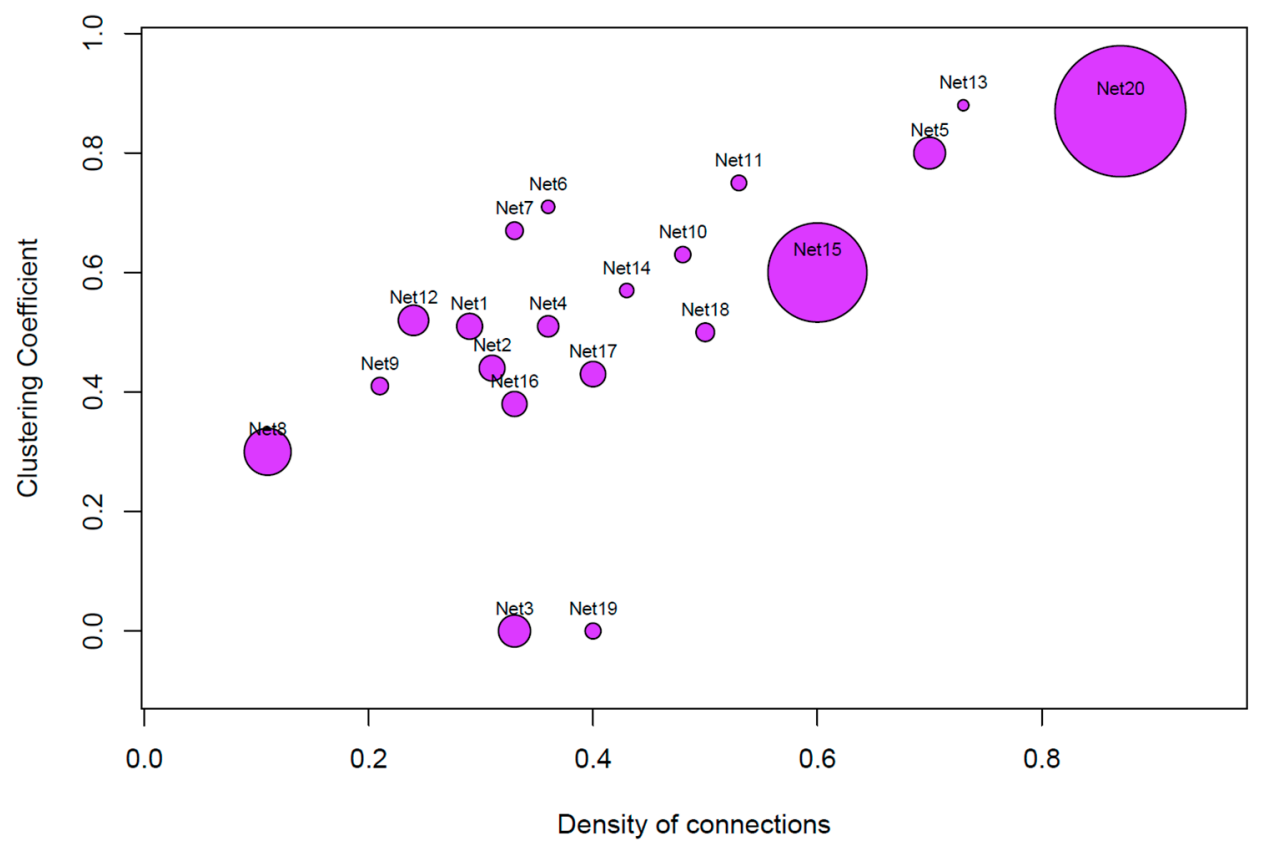

Figure 6. The relationship between network density, clustering coefficient and mean publications of each network. The vertical axis shows clustering coefficient, whose formula is $c l_{\mathrm{T}}(G)=3 \tau \Delta(G) / \tau_{3}(G)$. The horizontal axis shows density, whose formula is density $=2 l /[n(n-1)]$. The size of the circle is equivalent to the mean publications of the co-authorship networks.

It is clear from the chart that there is no large circle in the lower right quadrant. There are some possible ways one can interpret this observation. First, it is possible that clustering and density might not have a strong enough connection with how productive a co-authorship network could be; thus, this approach to identify sustainable research networks might not be helpful. Second, it could also be the case that collecting data of 412 scientists in 10 years is not enough to investigate the matter; observing the movement of the network metrics over a number of years would provide a much clearer picture with regards to social sustainability of the research groups. The third possibility is the approach could be right and one can infer that no candidate is qualified to be regarded as a sustainable research network in 412 social sciences in Vietnam. This is probable given how poorly social sciences in Vietnam have performed up until now [8-10]. In the next section, using the measure of social sustainability distance proposed in the previous section, it is hoped that insights into the status of social sustainability in Vietnamese social sciences communities could be unveiled.

\subsection{Social Sustainability Distance}

Recall that, in a co-authorship network, any author's position could be defined using three quantities: number of publications, connections in the network and years of research. The assumption is, in a sustainable network of co-authors, the distance among the most productive ones and the rest should not be too great. In this paper, five measurements for this distance are calculated: distance from the most productive researchers to the mean, the median, the min, the second most productive and the mean of the junior group (consists of people with equal or less than 3 publications). Table 2 summarizes the results. 
Table 2. Social sustainability distance (SSD) measures and other attributes for 20 research networks of Vietnamese social scientists.

\begin{tabular}{cccccccc}
\hline Network & Max-Mean & Max-Median & Max-Min & Max-2nd & Max-Junior & No. Nodes & Mean Publications \\
\hline Net1 & 9.38 & 11.05 & 12.41 & 6.71 & 12.21 & 11 & 3.91 \\
Net2 & 22.99 & 30.41 & 30.41 & 28.86 & 25.55 & 10 & 3.9 \\
Net3 & 13.32 & 16.58 & 22.49 & 17.69 & 16.54 & 7 & 4.86 \\
Net4 & 9.19 & 11.36 & 14.76 & 8.60 & 11.29 & 10 & 3.2 \\
Net5 & 10.37 & 10.49 & 21.75 & 10.49 & 16.89 & 5 & 2 \\
Net6 & 13.69 & 26.93 & 26.93 & 25.20 & 16.53 & 19 & 2.64 \\
Net7 & 14.01 & 12.53 & 12.53 & 32.02 & 13.67 & 11 & 7.1 \\
Net8 & 44.63 & 57.88 & 50.72 & 29.07 & 50.44 & 29 & 2.6 \\
Net9 & 16.02 & 16.16 & 16.16 & 11.22 & 17.41 & 15 & 2.43 \\
Net10 & 9.73 & 18.36 & 7.07 & 16.16 & 11.30 & 7 & 4.6 \\
Net11 & 3.82 & 7.14 & 19.26 & 7.14 & 4.58 & 6 & 1.67 \\
Net12 & 10.97 & 11.40 & 17.69 & 5.39 & 14.47 & 15 & 2.14 \\
Net13 & 2.13 & 1.41 & 6.40 & 1.41 & 2.13 & 6 & 7 \\
Net14 & 2.45 & 6.16 & 12.73 & 14.35 & 3.53 & 5 & 3.78 \\
Net15 & 48.10 & 59.21 & 62.03 & 58.86 & 61.52 & 5 & 3.83 \\
Net16 & 12.23 & 12.88 & 15.26 & 15.59 & 14.16 & 9 & 2.8 \\
Net17 & 8.18 & 9.22 & 13.04 & 9.22 & 10.01 & 6 & 19.83 \\
Net18 & 4.63 & 14.07 & 14.07 & 3.32 & 6.75 & 5 & 5 \\
Net19 & 3.97 & 10.49 & 11.87 & 10.49 & 4.60 & 6 & 5.3 \\
Net20 & 30.54 & 31.64 & 49.38 & 25.06 & 49.38 & & 6 \\
\hline
\end{tabular}

In Table 2, if we look at top 3 research networks in terms of the mean of publications-Net8, Net15, Net20-based on SSD, one can tell that Net15 is less sustainable than the other two. Net15 has only 5 members but SSD Max-2nd is about two times as much as the other two: 58.86 compared with 29.07 of Net8 and 25.06 of Net20. This measure shows such vast distance from the most productive member of Net15 to even the number two in terms of publications; for a group to maintain this huge gap among its members over 10 years, it shows a sign of unsustainable co-authoring behavior.

In the case of groups with small SSD, Net13 stands out as with lowest measures in all aspects: 2.13 for Max-Mean or 1.41 for Max-2nd for example. However, this is also a group with the lowest mean number of publications, 1.67 .

To keep on investigating, what SSD measures could tell us about social sustainability of research networks, next, we plot all SSD measures of 20 networks on a radar chart in Figure 7.

From Figure 7, it is quite obvious that across all networks, if the social sustainability distance is high in one kind of measurement, it is likely to be high in all others. This pattern holds even when the networks can differ significantly in various properties (see Table 2). One then can infer that over the period of 10 years, the most productive researchers tend to accelerate away from everyone else in the network and the gap would remain. From this data, one can make an educated guess that it is not easy to close the gap even between the most productive researcher and the second most productive one. This might be caused by the inefficient knowledge transfer among the researchers in co-authorship networks in social sciences in Vietnam, which implies a quite socially unsustainable situation. 


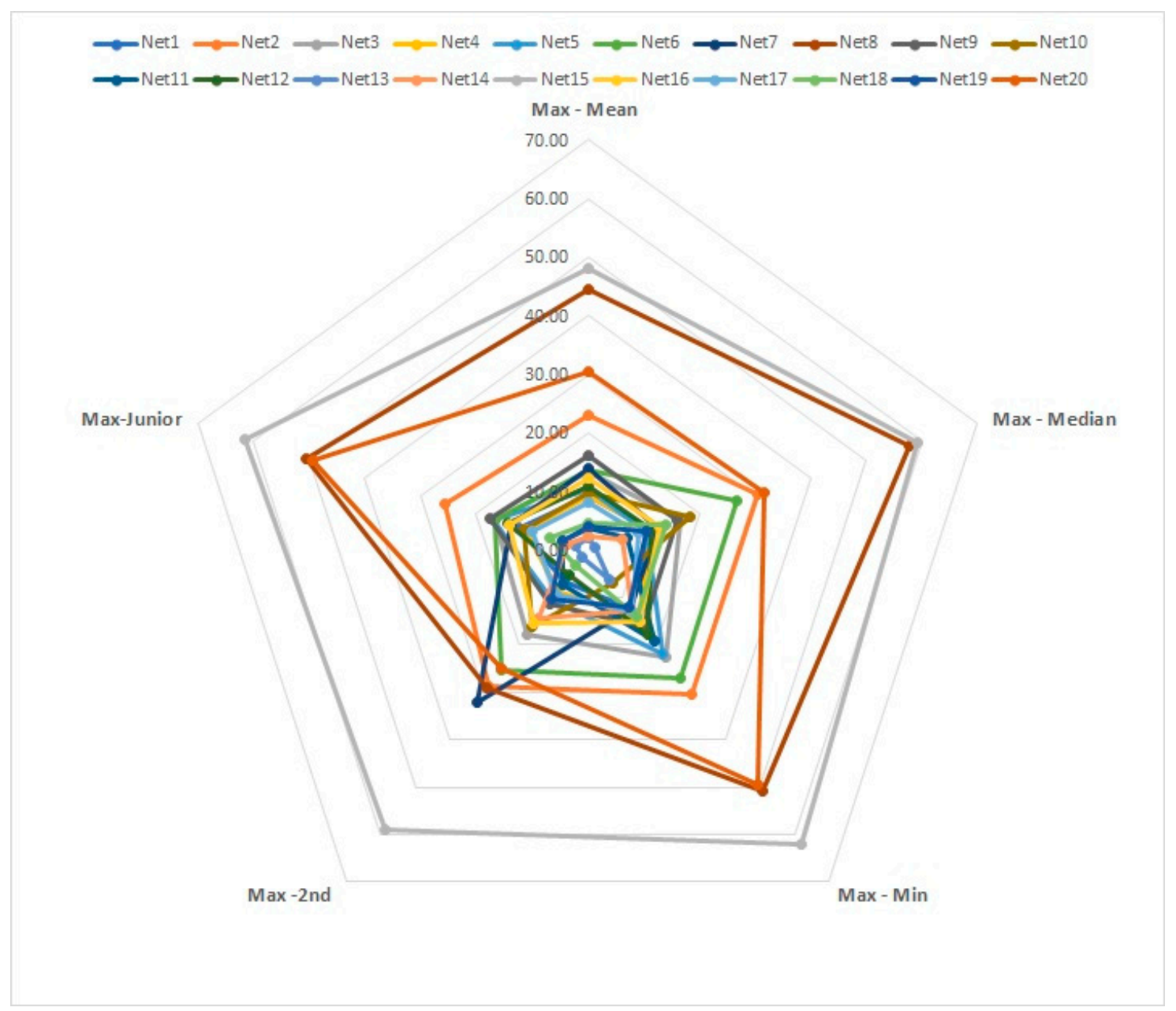

Figure 7. A radar chart plotting the different measures of social sustainability distance of 20 networks among Vietnamese social scientists.

\section{Discussion}

\subsection{Policy Implications for Vietnam}

As we have seen in the introduction, the Vietnamese government has recently pursued science policies that incentivize international publications and strong research groups [1-3]. Hence, the ability to identify and create sustainable research groups will become central for policy-making in order for this area to be effective. Although the results presented in this study are still preliminary, the network standard measures and the proposed measures have offered a novel approach to address this issue. The density of connections, clustering coefficient, and social sustainability distance allow us to glimpse and compare the structure and dynamics of the groups in a rather holistic way. This has allowed for the identification of two ways in which a research group could be unsustainable: the gap among its members in terms of productivity, connections and research years are either too large or too small.

In addition, as shown in the results, the patterns of SSD suggests that the most productive members of research groups tend to accelerate away from all others, even the second highest ones. This understanding could help policy-makers form training programs and create incentives to encourage the less established researchers.

Similar to the world, Vietnamese society is taken by surprise with the speed of technological progress, which has created new and unforeseen social problems. In this context, the ability of Vietnamese social scientists to address these new problems will be essential for the country to continue 
making social progress in the coming years. Consequentially, for Vietnam, solving the problem of science funding and policy is not only the matter of improving the quality of academic research but also a matter of improving the odds that the country will thrive when facing the challenges of a new era.

\subsection{On Applicability of SSD Metrics in an Ever-Technologically Advanced World}

In life, whenever there is a gap, there is a potential place for problems to arise, yet, a certain level of the gap is acceptable or even desirable. The question of social sustainability is really about finding how big a gap is sustainable for a complex social system. This is indeed a difficult and also the most central problem to the time we are living in. The world is witnessing such acceleration of technological progress that most humans find it hard to keep up [41,42,44]. There is, without a doubt, a societal problem with the gap of understanding technology: the gap between the most scientific and technological adept and the laypeople. An increasing number of people whose lives are governed by technologies do not understand them well, while the elites who understand technologies could exploit the gap to their benefits. Though the study does not provide a direct diagnosis for this gap of understanding technology, the measurement of social sustainability distance is a suggestion for how the gap could be measured.

\section{Limitations and Future Research Directions}

\subsection{Refining and Extending Measurements of Social Sustainability Distance}

For any new way of measuring, especially of such an elusive concept as social sustainability, it is certainly not without risks of being wrong and misguided. Therefore, it is imperative to cover as much empirical ground as possible by refining the measure of $S S D$ as well as extending it. In terms of refining the measure, one can renormalize the measure by dividing the deduction of two quantities by the larger quantity. The new formula for a refined SSD metric can have the form as displayed by Equation (4):

$$
S S D_{\text {renormalized }}=\sqrt{\left(\frac{x_{\max }-x_{0}}{x_{\max }}\right)^{2}+\left(\frac{y_{\max }-y_{0}}{y_{\max }}\right)^{2}+\left(\frac{z_{\max }-z_{0}}{z_{\max }}\right)^{2}} .
$$

As we have seen in Figure 3, the most productive members seem to always be central to many connections within a co-authorship network; in this study, we reasoned that the distance from the most productive member to the rest should be the most telling in terms of social sustainability and focused exclusively on this gap. However, to check against this assumption, one can explore options other than those appeared in this study, for example, mean-min, median-min, 2nd highest to mean, etc. Carrying out empirical investigations in this way would help us test the proposed measure in this study against all available options, thus finding out which one is the most reliable in helping us understand the social sustainability of research groups.

\subsection{More Advanced Application of Social Network Analysis}

This study cannot claim to have fully utilized the power of the social network analysis. The study is limited to whether or not there exists a co-authorship connection and has not taken into account the weight of each co-authorship connection, which is defined as the number of times two authors published together. In social network analysis literature, techniques to study weighted connections have been well-developed [82]. One could well see this dimension of connection intensity among scholars could yield new insights into the social sustainability of the research communities.

Related to the question of social sustainability, another aspect of co-authorship network that is worth exploring is the direction of the co-authorship connections. In this study, all connections among authors are treated as equal, i.e., there is no need to specify the order of two nodes that define an edge. However, in the real world, it is common that the first author or the corresponding author of a paper 
has a leadership role. One can argue that a sustainable research network would have a relatively high level of reciprocity among co-authors rather than a few authors dominantly play the leadership role. Hence, when this dimension of connection directionality is added into the analysis, network metric such as co-authoring reciprocity will help us achieve the deeper understanding of social sustainability of a network. In addition, we must not forget that experienced authors are also likely to play the role of peer-reviewers; and this aspect could become potentially influential to both productivity and the modality of mentoring and collaboration, in an increasingly connected scholarly community [85].

\subsection{Further Development of Empirical Strategies}

It might be the case that the data collected for 412 Vietnamese social scientists is not enough to allow a truly thorough empirical investigation of the concepts and the measurements explored in this study. Consequently, the results of the study are limited to be only indicative of the situation of social sustainability of the research communities in social sciences in Vietnam. This problem can be solved by developing more advanced empirical strategies. For example, instead of investigating one block of time from 2008-2017, one can divide the block into smaller chunks of 3 years each. In this way, one can investigate how SSD metrics and clustering coefficient change over the years; as such, giving a better sense of how the research networks evolve or deteriorate. One can also study the problems raised in the study longitudinally by collecting the data of 30 or even 50 years. By following the research networks over a long period of time, the theoretical assumptions raised in this study can then by fully tested against reality.

\section{Conclusions}

The study has developed a novel way to understand co-authorship behavior in Vietnam's social scientific communities as well as to evaluate their social sustainability. Using social network analysis, the study is able to address the two research questions posed in its premise.

First, the study uses the basic network metrics, namely clustering coefficient and density of connection, and extracts 20 communities with at least 5 members each from the total dataset to analyze the extent of social sustainability in Vietnamese social scientists' communities. The data shows there is no group with a high mean of publications, high density, and low clustering. As our initial assumption is that groups with high density and low clustering are sustainable, the data suggests a lack of social sustainability among research networks in Vietnam.

Second, based on the ground that any researcher's position in a network can be defined by three quantities: (i) number of publications, (ii) connections, and (iii) and years in research, the study calculates and compares the distance between the most productive researchers and the rest of the communities. If the distance between the most productive researcher and his or her remaining group members is too large or too small, this research network might be socially unsustainable.

While the metrics used in this study suggest some level of unsustainability within Vietnam's social science communities, they nonetheless offer for the first time a quantitative way to identify both the productivity and sustainability of the local research networks. In the future, proper development of the empirical strategies could yield a more complete picture of this matter, perhaps in conjunction with related statistical investigations into transformed data types such as categorical data for acquiring conditional probabilities [83].

Supplementary Materials: All data sets are available from Mendeley Data repository and open to the public at doi:10.17632/f3j6rn362v.2 [84] with the detailed explanation as follows:

Dataset 1: "Folder Net412's Data". This folder contains two files: "20170725_net412_NODES.csv" and "20170729_net412_LINKS.csv". The former lists all 412 individuals in the study and their attributes, each individual is considered a node (vertex) in the network. The latter lists the number of co-written articles between all 412 authors of the network, where relevant; each collaboration is counted as a link (edge) in the network.

Dataset 2: "Folder 20 Networks' Data". This folder includes all nodes lists and edges lists of 20 small networks extracted from the original.

Dataset 3: "Metrics all nets 20171003.csv" This dataset contains the summary of all metrics that represent 20 research networks in the study. 
Dataset 4: "Folder SSD Calculation". This folder contains four files: "Research network details 20171012.xlsx" contains the nodes lists for 20 research networks in the study as well as the calculations for the junior members of each network; "SSD Calculation details 20171012.xlsx" contains the details of SSD calculations for all networks, "SSD Summary 20171012.xlsx" is the summary of final results of calculations for all SSD measurements of 20 networks in the study.

Dataset 5: "Folder R-command and figure3" contains R commands and the PDF file of Figure 3.

Dataset 6: "Folder R-command and figure4" contains R commands and the PDF file of Figure 4.

Dataset 7: "Folder R-command and figure5" contains R commands and the PDF file of Figure 5.

Dataset 8: "Folder R-command and figure6" contains R commands and the PDF file of Figure 6.

Dataset 9: "Folder R-command and figure for all nets" contains the R commands files and the PDF files for all nets that did not appear in the final paper.

Acknowledgments: We would like to thank Vuong \& Associates for their research initiative The Network of Vietnamese Social Scientists ("NVSS"), which enabled the research process and provided the raw data for the study. We particularly thank Dam Thu Ha, Ho Manh Toan and Nghiem Phu Kien Cuong for their excellent research assistance. We thank Nancy K. Napier and Dam Quang Minh for their valuable comments. We are also grateful for useful comments from participants-who came from different academic disciplines-in the seminar "Beauty and the Light of Hope" co-organized by Western University Hanoi and Vuong \& Associates in Hanoi, on October 3, 2017, particularly Nguyen Tu Cuong (mathematics), Nguyen Ngoc Chau (biology), Pham Duc Chinh (mechanics), Khuat Thu Hong (sociology), Le Van Canh (linguistics), Nguyen Viet Cuong and Tran Quang Tuyen (economics), Hoang Anh Tuan Kiet (physics), Tran Kien (law), Bui Quang Khiem (fine arts), Nguyen Pham Muoi (journalism/media), Bach Ngoc Chien (public governance), to name just a few.

Author Contributions: Q.-H.V. conceived and designed the study; all contributors (T.M.H., H.K.T.N., T.-T.V., Q.-H.V.) contributed equally for the remaining tasks of the research and manuscript preparation, i.e., dataset preparation, analysis, interpreting results, and writing and checking the paper.

Conflicts of Interest: The authors declare no conflict of interest.

\section{References}

1. Ministry of Education and Training. Circular Number 08/2017/TT-BGDĐT, Issued on 4 April 2017, by Minister of Education and Training. Available online: https://moet.gov.vn/van-ban/vanban/Pages/chitiet-van-ban.aspx?ItemID=1249 (accessed on 10 October 2017).

2. Nhan, T. NAFOSTED invests in strong research teams. Tia Sang. 24 August 2017. Available online: http:/ / tiasang.com.vn/-khoa-hoc-cong-nghe/NAFOSTED-dau-tu-cho-nhom-nghien-cuu-manh--10876 (accessed on 10 October 2017).

3. The National Foundation for Science and Technology Development (NAFOSTED). Circular Number 37/2014/TT-BKHCN, Issued on 12 December 2014, by Minister of Science and Technology. Available online: http:/ / www.nafosted.gov.vn/vi/archives/view/37242014TT-BKCN-26/ (accessed on 10 October 2017).

4. Ha, N. Reforming the criteria for the professorship titles: Time to change. Tuoi Tre Online. 27 March 2017. Available online: http:/ / tuoitre.vn/doi-moi-tieu-chuan-chuc-danh-giao-su-den-luc-phai-thay-doi-1287110. htm (accessed on 18 September 2017). (In Vietnamese)

5. Chinh, P.D. Reforming by raising the academic Standards right from inside of the State councils on professorship titles. Vietnamnet. 8 February 2017. Available online: http:/ /vietnamnet.vn/vn/giao-duc/ khoa-hoc/du-thao-moi-ve-quy-dinh-tieu-chuan-giao-su-pho-giao-su-cai-cach-nang-chuan-tu-chinhcac-hoi-dong-chuc-danh-giao-su-354890.html (accessed on 17 September 2017). (In Vietnamese)

6. Hanh, H.; Thu, L. Top 300 Asian Ranking: Why there have been no Vietnamese universities? Dan Tri. 29 March 2017. Available online: http://dantri.com.vn/su-kien/xep-hang-300-truong-dh-hang-dauchau-a-vi-sao-dai-hoc-viet-nam-chua-ghi-ten-20170329162534079.htm (accessed on 18 September 2017). (In Vietnamese)

7. Huong, L. Nowhere in the ranking, what happened with Vietnamese higher education? Giao Duc Viet Nam. 16 April 2017. Available online: http:/ / giaoduc.net.vn/Giao-duc-24h/Bang-xep-hang-khong-co-ten-daihoc-Viet-Nam-sao-the-nhi-post175835.gd (accessed on 18 September 2017). (In Vietnamese)

8. Diep, B. Debate around the 90 billion dong funding one internationally published article. Dan Tri. 27 April 2016. Available online: http:/ / dantri.com.vn/kinh-doanh/tranh-cai-quanh-90-ty-dong-cho-1-baibao-khoa-hoc-quoc-te-2016042707233457.htm (accessed on 18 September 2017). (In Vietnamese)

9. Thuy, H. Why Vietnam Academy of Social Sciences had too few international publications? Vnexpress. 23 April 2016. Available online: https://vnexpress.net/tin-tuc/giao-duc/vi-sao-vien-han-lam-khoa-hocxa-hoi-it-co-nghien-cuu-cong-bo-quoc-te-3391989.html (accessed on 18 September 2017). (In Vietnamese) 
10. Pham, Q.M. It is time to reform research in social sciences and humanities. Tia Sang. 24 January 2017. Available online: http:/ / tiasang.com.vn/-quan-ly-khoa-hoc/Da-den-luc-phai-doi-moi-trong-nghien-cuuKHXHNV-10389 (accessed on 18 September 2017). (In Vietnamese)

11. Nguyen, T.V.; Pham, L.T. Scientific output and its relationship to knowledge economy: An analysis of ASEAN countries. Scientometrics 2011, 89, 107-117. [CrossRef]

12. Yi, Y.; Qi, W.; Wu, D. Are CIVETS the next BRICs? A comparative analysis from scientometrics perspective. Scientometrics 2013, 94, 615-628. [CrossRef]

13. Manh, H.D. Scientific publications in Vietnam as seen from Scopus during 1996-2013. Scientometrics 2015, 105, 83-95. [CrossRef]

14. Nguyen, T.V.; Ho-Le, T.P.; Le, U.V. International collaboration in scientific research in Vietnam: An analysis of patterns and impact. Scientometrics 2017, 110, 1035-1051. [CrossRef]

15. Vuong, Q.H.; Ho, T.M.; Vuong, T.T.; Napier, N.K.; Pham, H.H.; Nguyen, H.V. Gender, age, research experience, leading role and academic productivity of Vietnamese researchers in the social sciences and humanities: Exploring a 2008-2017 Scopus dataset. J. Eur. Sci. Ed. 2017, 43, 51-55. [CrossRef]

16. Vuong, Q.-H.; Ho, T.M.; Vuong, T.-T.; Nguyen, H.V.; Napier, N.K.; Pham, H.-H. Nemo Solus Satis Sapit: Trends of research collaborations in the Vietnamese social sciences, observing 2008-2017 Scopus data. Publications 2017, 5, 24. [CrossRef]

17. Ho, T.M.; Nguyen, H.V.; Vuong, T.T.; Dam, Q.M.; Pham, H.H.; Vuong, Q.H. Exploring Vietnamese co-authorship patterns in social sciences with basic network measures of 2008-2017 Scopus data. F1000Research 2017, 6, 1559. [CrossRef] [PubMed]

18. Vuong, Q.H.; Napier, N.K. Making creativity: The value of multiple filters in the innovation process. Int. J. Transit. Innov. Syst. 2014, 3, 294-327. [CrossRef]

19. Vuong, Q.H.; Napier, N.K. Acculturation and global mindsponge: An emerging market perspective. Int. J. Intercult. Relat. 2015, 49, 354-367. [CrossRef]

20. Vuong, Q.H. Global mindset as the integration of emerging socio-cultural values through mindsponge processes: A transition economy perspective. In Global Mindset: Exploration and Perspectives; Kuada, J., Ed.; Routledge: New York, NY, USA, 2008; pp. 109-126.

21. Lafferty, W.M. (Ed.) Governance for Sustainable Development: The Challenge of Adapting Form to Function; Edward Elgar: Cheltenham, UK, 2004.

22. Brundtland, G.H. Report of the World Commission on Environment and Development: Our Common Future; Oxford University Press: Oxford, UK, 1987; ISBN 019282080X.

23. Robinson, J. Squaring the circle? Some thoughts on the idea of sustainable development. Ecol. Econ. 2004, 48, 369-384. [CrossRef]

24. Holden, E.; Linnerud, K.; Banister, D. Sustainable development: Our common future revisited. Glob. Environ. Chang. 2014, 26, 130-139. [CrossRef]

25. Walker, P. Sustainability: A discipline and a political agenda? Environ. Hazards 2017, 16, 93-98. [CrossRef]

26. Mebratu, D. Sustainability and sustainable development: Historical and conceptual review. Environ. Impact Assess. Rev. 1998, 18, 493-520. [CrossRef]

27. Sneddon, C.; Howarth, R.B.; Norgaard, R.B. Sustainable development in a post-Brundtland world. Ecol. Econ. 2006, 57, 253-268. [CrossRef]

28. Union of Concerned Scientists. Available online: http://www.ucsusa.org/ (accessed on 20 September 2017).

29. Malthus, R.T. An Essay on the Principle of Population; J. Johnson: London, UK, 1798.

30. Ehrlich, P.R. The Population Bomb; Ballantine Books: New York, USA, 1968.

31. Meadows, D.H.; Meadows, D.L.; Randers, J.; Behrens, W.W. The Limits to Growth; The Universe Books: New York, NY, USA, 1972.

32. Tainter, J. The Collapse of Complex Societies; Cambridge University Press: Cambridge, UK, 1988.

33. Diamond, J. Collapse: How Societies Choose to Fail or Succeed; Penguin: New York, NY, USA, 2005.

34. Marx, K.; Engel, F. Alienation and social classes (from the Holy Family). In The Marx-Engels Reader, 2nd ed.; Tucker, R.C., Ed.; W.W. Norton \& Company: New York, NY, USA, 1972.

35. Stiglitz, J.E. The Price of Inequality: How Today's Divided Society Endangers Our Future; W.W. Norton \& Company: New York, NY, USA, 2012; ISBN 978-0-393-34506-3.

36. Piketty, P. Capital in the 21st Century; Harvard University Press: Cambridge, MA, USA, 2013. 
37. Wilkinson, R.G.; Pickett, K. The Spirit Level: Why More Equal Societies Almost Always Do Better; Allen Lane: London, UK, 2009.

38. Freeland, C. Plutocrats: The Rise of the New Global Super-Rich and the Fall of Everyone Else; Doubleday Canada: Toronto, ON, Canada, 2012.

39. Bostrom, N. Existential risk prevention as global priority. Glob. Policy 2013, 1, 15-31. [CrossRef]

40. Posner, R.A. Catastrophe: Risk and Response; Oxford University Press: Oxford, UK, 2004.

41. Rees, M.J. Our Final Hour: A Scientist's Warning-How Terror, Error, and Environmental Disaster Threaten Humankind's Future in This Century—On Earth and Beyond; Perseus Books Group: New York, NY, USA, 2004.

42. Bostrom, N.; Cirkovic, M. Global Catastrophic Risks; Oxford University Press: New York, NY, USA, 2008.

43. Elkington, J. Towards the sustainable corporation: Win-win-win business strategies for sustainable development. Calif. Manag. Rev. 1994, 36, 90-100. [CrossRef]

44. Tegmark, M. Life 3.0: Being Human in the Age of Artificial Intelligence; K. Doubleday: New York, NY, USA, 2017.

45. Bettencourt, L.; West, G. A unified theory of urban living. Nature 2010, 467, 912-913. [CrossRef] [PubMed]

46. Whitemarsh, L. Behavioural responses to climate change: Asymmetry of intentions and impacts. J. Environ. Psychol. 2009, 29, 13-23. [CrossRef]

47. Stern, P.C. New environmental theories: Toward a coherent theory of environmentally significant behavior. J. Soc. Issues 2000, 56, 407-424. [CrossRef]

48. Whitmarsh, L.; O'Neill, S. Green identity, green living? The role of pro-environmental self-identity in determining consistency across diverse pro-environmental behaviours. J. Environ. Psychol. 2010, 30, 305-314. [CrossRef]

49. Barreto, M.L.; Szóstek, A.; Karapanos, E.; Nunes, N.J.; Pereira, L.; Quintal, F. Understanding families' motivations for sustainable behaviors. Comput. Hum. Behav. 2014, 40, 6-15. [CrossRef]

50. Grønhøj, A.; Thøgersen, J. Why young people do things for the environment: The role of parenting for adolescents' motivation to engage in pro-environmental behaviour. J. Environ. Psychol. 2017, 54, 11-19. [CrossRef]

51. Blake, J. Overcoming the 'value-action gap' in environmental policy: Tensions between national policy and local experience. Local Environ. 1999, 4, 257-278. [CrossRef]

52. Kollmuss, A.; Agyeman, J. Mind the gap: Why do people act environmentally and what are the barriers to pro-environmental behavior? Environ. Educ. Res. 2002, 8, 239-260. [CrossRef]

53. Newton, P.; Meyer, D. Exploring the attitudes-action gap in household resource consumption: Does "Environmental Lifestyle" segmentation align with consumer behaviour? Sustainability 2013, 5, 1211-1233. [CrossRef]

54. Gifford, R. The dragons of inaction: Psychological barriers that limit climate change mitigation and adaptation. Am. Psychol. 2011, 66, 290. [CrossRef] [PubMed]

55. Rees, W. Whats blocking sustainability? Human nature, cognition, and denial. Sustain. Sci. Pract. Policy 2010, 6, 13-25. [CrossRef]

56. Markowitz, E.M.; Shariff, A.F. Climate change and moral judgement. Nat. Clim. Chang. 2012, 2, $243-247$. [CrossRef]

57. Deutsch, D.E. The Beginning of Infinity: Explanations That Transform the World; Viking: New York, NY, USA, 2011.

58. Edge. Why cities keep growing, corporations and people always die, and life gets faster. Edge Conversation. 23 May 2011. Available online: https://www.edge.org/conversation/geoffrey_west-why-cities-keepgrowing-corporations-and-people-always-die-and-life-get (accessed on 4 September 2017).

59. West, G. Universal scaling laws from cells to cities: A physicist's search for quantitative, unified theories of biological and social structure and dynamics. Bull. Am. Phys. Soc. 2013, 58. ID: BAPS.2013.APR.F4.1. Available online: http://absimage.aps.org/image/APR13/MWS_APR13-2013-020103.pdf (accessed on 20 November 2017).

60. Ball, P. Complexity: Decoding deep similarities. Nature 2017, 545, 154-155. [CrossRef]

61. Nica, E.; Potcovaru, A.M. The social sustainability of the sharing economy. Econ. Manag. Financ. Mark. 2015, 10,69-75.

62. Hollander, R.; Amekudzi-Kennedy, A.; Bell, S.; Benya, F.; Davidson, C.; Farkos, C.; Quigley, D. Network priorities for social sustainability research and education: Memorandum of the Integrated Network on Social Sustainability Research Group. Sustain. Sci. Pract. Policy 2016, 12, 16-21. [CrossRef] 
63. Almahmoud, E.; Doloi, H.K. Assessment of social sustainability in construction projects using social network analysis. Facilities 2015, 33, 152-176. [CrossRef]

64. Hutchins, M.J.; Sutherland, J.W. An exploration of measures of social sustainability and their application to supply chain decisions. J. Clean. Prod. 2008, 16, 1688-1698. [CrossRef]

65. Magis, K. Community resilience: An indicator of social sustainability. Soc. Nat. Resour. 2010, 23, 401-416. [CrossRef]

66. Vallance, S.; Perkins, H.C.; Dixon, J.E. What is social sustainability? A clarification of concepts. Geoforum 2011, 42, 342-348. [CrossRef]

67. Weingaertner, C.; Moberg, Å. Exploring social sustainability: Learning from perspectives on urban development and companies and products. Sustain. Dev. 2014, 22, 122-133. [CrossRef]

68. Karol, E.; Brunner, J. Tools for measuring progress towards sustainable neighborhood environments. Sustainability 2009, 1, 612-627. [CrossRef]

69. Turcu, C. Re-thinking sustainability indicators: Local perspectives of urban sustainability. J. Environ. Plan. Manag. 2013, 56, 695-719. [CrossRef]

70. Newman, M.E. Scientific collaboration networks. I. Network construction and fundamental results. Phys. Rev. E Stat. Nonlinear Soft Matter Phys. 2001, 64 Pt 2, 016131. [CrossRef] [PubMed]

71. Kajikawa, Y.; Ohno, J.; Takeda, Y.; Matsushima, K.; Komiyama, H. Creating an academic landscape of sustainability science: An analysis of the citation network. Sustain. Sci. 2007, 2, 221. [CrossRef]

72. Moody, J. The structure of a social science collaboration network: Disciplinary cohesion from 1963 to 1999. Am. Sociol. Rev. 2004, 69, 213-238. [CrossRef]

73. Li, E.Y.; Liao, C.H.; Yen, H.R. Co-authorship networks and research impact: A social capital perspective. Res. Policy 2013, 42, 1515-1530. [CrossRef]

74. Ding, Y. Scientific collaboration and endorsement: Network analysis of coauthorship and citation networks. J. Informetr. 2011, 5, 187-203. [CrossRef] [PubMed]

75. Ingold, K.; Balsiger, J. Sustainability principles put into practice: Case studies of network analysis in Swiss climate change adaptation. J. Reg. Environ. Chang. 2015, 15, 529-538. [CrossRef]

76. Wu, X.; Liu, Z. How community structure influences epidemic spread in social networks. Phys. A Stat. Mech. Appl. 2008, 387, 623-630. [CrossRef]

77. Scott, J. Social Network Analysis, 4th ed.; Sage: London, UK, 2017.

78. Official Website of the National Foundation for Science and Technology Development. Available online: http:/ / www.nafosted.gov.vn/en/about-us / (accessed on 17 November 2017).

79. Scopus. CiteScore Metrics Infographics. Available online: https://www.elsevier.com/_data/assets/pdf_ file/0008/308294/CiteScore_Infographic.pdf (accessed on 17 November 2017).

80. Clarivate Analytics. 2017 Journal Citation Reports. Available online: http://clarivate.com/?product= journal-citation-reports (accessed on 17 November 2017).

81. Freeman, L.C. The Development of Social Network Analysis: A Study in the Sociology of Science; Empirical Press: Vancouver, BC, Canada, 2004.

82. Kolaczyk, E.D.; Csárdi, G. Statistical Analysis of Network Data with R; Springer: New York, NY, USA, 2014.

83. Vuong, Q.H. Survey data on Vietnamese propensity to attend periodic general health examinations. Sci. Data 2017, 4, 170142. [CrossRef] [PubMed]

84. Vuong, Q.H. Data and supplementary materials for the network of 412 Vietnamese social scientists indexed in Scopus database 2008-2017. Mendeley Data 2017, 2. [CrossRef]

85. Vuong, Q.H. Learning to love the reviewer. J. Eur. Sci. Ed. 2017, 43, 83.

(C) 2017 by the authors. Licensee MDPI, Basel, Switzerland. This article is an open access article distributed under the terms and conditions of the Creative Commons Attribution (CC BY) license (http://creativecommons.org/licenses/by/4.0/). 